\title{
From Order to Delivery: An Integrated Process Approach for Customer Satisfaction
}

\author{
Gilles Neubert, Andréa Wattky Crestan, and Abdelaziz Bouras \\ University of Lyon2, PRISMA laboratory IUT Lumière, \\ 160 bd de l'université, 69676 Bron, France
}

\begin{abstract}
Today, companies are evolving towards business process oriented organization. This approach relies on integration and collaboration between interdependent activities that must be redesign and managed to increase the performance of the global system. After some consideration about integration, collaboration and business process re-design, this paper will present a case study that concerns the reorganization of the European commercial assistantship, the logistics and transport office as well as the production planning of a world-leading chemical company, for better customer satisfaction.
\end{abstract}

Key words: Business Process Reengineering, Collaboration, Integration,

\section{Introduction}

Business environment has changed in the past decades and is more complex and unforeseeable than ever. In this new century companies are led to believe that the most valuable characteristic of an organization is its ability to adapt to the dynamic environment in which they operate. To be successful, each company needs to work as a team where all the functional areas of the business are properly integrated. These last years, much attention has been focused on the management methodology of supply chain management (SCM), which integrates business processes from suppliers to customers and manages various tasks, such as sales, manufacturing, logistics, and finance. Integration and business process management look like the new issue in the problem of designing and operating modern industrial systems. As identify by Lindsay et al. (2003), much of the literature produced by the business process management and reengineering (BPM/R) community suggests that implementing process orientated structures will help organizations to be more responsive to an increasingly changing environment.

Please use the following format when citing this chapter:

Neubert, G., Crestan, A.W. and Bouras, A., 2008, in IFIP International Federation for Information Processing, Volume 257, Lean Business Systems and Beyond, Tomasz Koch, ed.; (Boston: Springer), pp. 337-345. 
The transition of the company organization for more integration between company functions and services has had as consequence the emergence of BPR. It means the reorganization of the company organization in order to transform it from a vertical silo organization, with independent functions and services, into a horizontal organization that is based on transverse processes (Kramer and Tyler, 1995).

This paper aims at describing a large scale Business Process Reengineering that encompasses the European Sales department, the Logistics department, and the Operations Planning department of a major actor of the chemical industry. The objective was a better description of the global process from the customer order to the customer delivery in order to improve its efficiency and increase the "On Time In Full” (OTIF) Key Performance Indicator.

The next section will address the concept of integration and coordination that support business process approach, when section 3 will describe a case study of business process redesign to increase customer satisfaction while reducing the company's organization complexity. Section 4 will conclude this paper.

\section{Business Process Approach}

BPR supposes the interdependency of company services and functions and looks for reaching significant improvement in critical performance measures (Mentzer, 1999). Literature witnesses this phenomenon and several books confirm this tendency (Hammer and Champy, 1993), (Stevens, 1989), (Davenport, 1993). BPR is a process approach that concerns internal modifications of the company organization in order to attain better integration and internal collaboration within the organization.

\subsection{Integration}

The concept of integration can be approached through different perspectives (functional, business process, Information System, etc.), but in all cases, it aims at shifting from local management to system management. From literature, it emerges that integration can support business processes at two different levels (Romano, 2003):

1. intra-company integration, aiming to overcome the functional silos boundaries, and relating to activities to manage and re-design the business processes across the individual members of the supply network.

2. inter-companies integration, aiming to overcome the individual company boundaries, and relating both to a initial extent of integration, or "intercompanies dyadic integration", and to an advanced extent of integration, or " overall supply network integration".

\subsection{Coordination}

As described by Danese et al. (2004), how to achieve efficient and effective coordination among the various activities in business processes within companies is 
one of the issues most thoroughly investigated by organizational researchers. Coordination is particularly problematic when considering supply networks, as the scope of business processes overcomes the individual company's boundaries. In this case, the complexity of coupling different companies within supply networks combines with the complexity arising from how within-firm elements (e.g. divisions and departments) are linked together. As proposed by Lambert et al. (1998) and developed by Choi and Hong (2002), managers simultaneously face three different forms of structural complexity in supply networks: vertical, horizontal and spatial. Vertical complexity refers to the number of levels in the whole system (i.e. the number of tiers), horizontal complexity refers to the number of different entities in the same level of the supply network (e.g. number of suppliers in each tier), and spatial complexity refers to the average distance between operating locations. Thus, managing business processes across supply networks is a very complex task that requires managers to properly activate coordination mechanisms to adapt, align and synchronize activities carried out by the different and interdependent members of the network (Danese et al., 2004).

Starting from a broad definition of coordination, "the act of working together harmoniously", Malone and Crowston (1990) proposed several components of coordination : there must be one or more actors, performing some activities which are directed toward some goals, the word "harmoniously," referring to the fact that activities are not independent. They defined these goal-relevant relationships between the activities as interdependencies and they proposed a definition of coordination as "the act of managing interdependencies between activities performed to achieve a goal ».

Their work (Malone and Crowston 1994) and other previous works such as the work from Thompson (1967), lead to the definition of some standard types of interdependencies. Frayret et al (2004) proposed a summary of the main types of interdependence. First, the most commonly cited type of interdependence concerns organizational resources sharing. It is related to the concept of pooled interdependence (Thompson 1967), in which each part of a system renders a discrete contribution to the whole, while each part is supported by the whole. Another type of interdependence concerns the producer-consumer relationship (Malone and Crowston 1994), or sequential interdependence (Thompson 1967). This type links two manufacturing activities for which the output of one is the input of the other. Another type of interdependence called reciprocal relationships concerns activities whose outputs are the reciprocal inputs of the other activity. Next, intensive interdependence is related to the intrinsic sophistication of activity embeddedness (Grandori 1997). In distributed manufacturing, this type of interdependence occurs when the activities distributed among centers are highly connected in terms of time requirement, reciprocity, output/input transfer, or input usability.

\subsection{Customer satisfaction and Business process Design}

According to Davenport (1993), a process « is simply a structured set of activities designed to produce a specified output for a particular customer or market ». A process thus consists in multi-actor activities, which are carried out through 
time and space; the links between these activities and the activities them-selves may belong to different functions, different production site or even to different organizations. In that sense, following Malone and Crowston definition, it is a set of linked activities, and, managing a process consists in managing interdependencies between activities performed to achieve a goal.

By restructuring their processes, companies pursue the objective of releasing financial resources, reduce costs, lighten the company management, and improve global performance (Palvia, 1995), (Lacity and Hirschheim, 1993), (Rittenberg and Covaleski, 2001).

Looking at Customer satisfaction as the goal, managing the process to reach this goal consists in managing the interdependency between activities that contribute to this goal. Business processes can be described at different levels of detail depending on the abstraction put into analyzing the organization, which depends in turn on the purpose of the analysis. In the case of Business process Reengineering, the goal is not only to better manage the actual activities interdependency, but also to redesign this set of activities, their contains, to simplify the flow of information and to reduce the complexity of the entire process.

As modeling the processes from scratch is a hard task, the SCOR-model (Supply Chain Operations Reference-model) was used because it describes with standard component (Processes, Activities, Best practice, Performance Indicators,..) an ideal process state, which can be reached or adapted through an "as is" process analysis and reorganization of that process. Hence, the company attains, regarding to its own strategy and constraints, the "to be" process thanks to a comparison and analysis of its actual processes with the processes proposed by SCOR.

\section{Process and organization redesigning: case study}

With research and production centers in France, USA, China and Japan, a worldleading manufacturer of products containing fourteen different rare earths, Rhodia Electronics \& Catalysis' (REC) is quite complex. Many products are produced in small a quantity, which has an important impact on the production process flow. Insufficient inventory and inadequate supply may thus have direct consequences on delivery delays and thus on customer satisfaction.

The objective of REC's process simplifying concerned the European commercial assistantship, the logistics and transport office as well as the production planning and scheduling office, which were considered as essential for the company's competitive advantage. Within this context, the supply chain process redesigning of the company's production site was seen as the means to clarify and to improve the process from order processing to product delivery.

\subsection{As Is situation}

As noticed earlier, BPR and the SCOR-model suppose the description and analysis of actual processes in order to understand them and transform them into redesigned processes with better performance. REC's initial organization was 
complex (Figure 1) and needed more integration within the company. The process reengineering efforts concerned all activities, from the customer order down to the customer delivery. Those include order acknowledgement and processing, charge capacity evaluation, transport planning and scheduling, order tracing, packaging, shipping and invoicing.

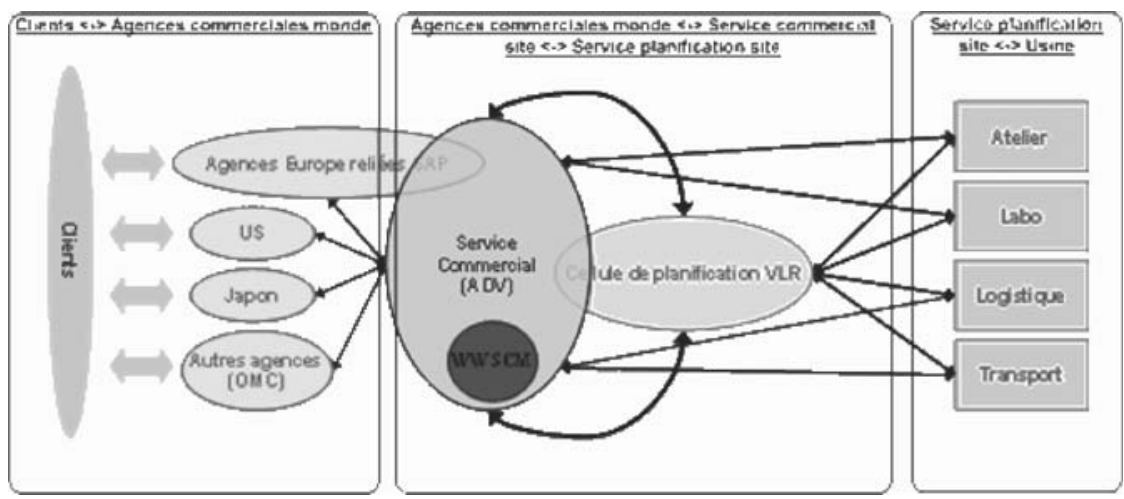

Fig. 1. «As is » company organization

Three different entities of the company were concerned:

- The worldwide commercial assistantship offices, in direct contact with customers: customer support, salesmen support, order registration, commercial forecasts, invoicing and claim follow-up, etc.

- The production site's commercial assistantship office, in contact with the worldwide offices as well as the production planning and scheduling office: assistantship office interfaces, order entry for assistantship offices that are not linked to the site's information system, order follow-up, product allotment management, business unit support, data base maintenance, etc.

- Manufacturing plant (production, product analyzing office, and logistics and transport office), organized through workshops and in contact with the production planning and scheduling office: interfaces with planning and scheduling office, sub-contracting management, information system data base maintenance, product and rare earth requirement coordination, etc.

The company's objective was to move the organization from the three distinct entities (European Sales department, logistics department and the operations planning department) to two integrated entities: 1) Sales Management, and a so called 2) Product coordination department in order to better coordinate sales, production planning, and distribution.

Analyzing the difference between the "as is" situation and the flow proposed by SCOR enables to find differences in the sequence of activities, or missing of some activities or execution of one activity by another actor or department. This gives good indication on the needed reorganization of the activities or on the 
understanding of the barriers in the process structure, its fluidity bottlenecks and their impact on the performance.

\subsection{Process redesigning objectives}

A deeper analysis has then being done to verify that all the needed information is used and available to manage activities. Although the SCOR-Model is not an Information System Model, it gives many details about data used and created by each activity in the process. The benchmark between actual data and information involved in the process and SCOR recommendation was useful in understanding any missing one for the new process.

The redesigning objectives concerning the three entities were thus the following:

- Clarify the roles and responsibilities of the worldwide commercial assistantship office, the site's assistantship office as well as the production planning and scheduling office

- Avoid double work and improve interfaces and interactions between the different offices in order to establish a transverse process flow of the delivery process ( from order entry to product delivery to the customer)

- Improve the sub-process and activities within this process for a better customer service

The initiative for process redesigning consisted in the establishment of a unique assistantship office, located at the production site, by regrouping the different European offices. After the reorganizing effort from the initial three entities only two of them were left (Figure 2):

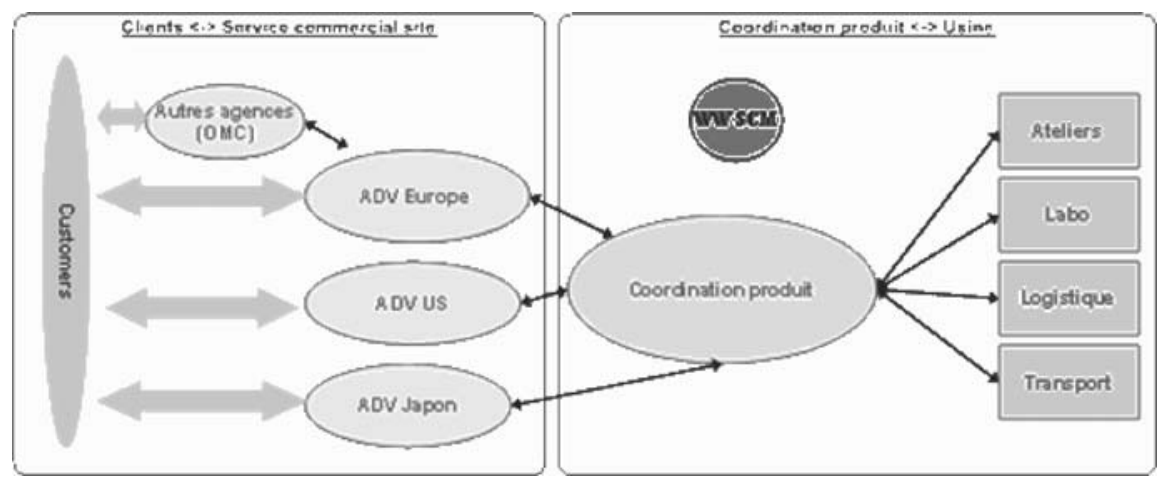

Fig. 2 . « To be » company organization

- One commercial assistantship office (and only a limited number of worldwide offices) in direct interaction with customers: salesmen support, quoting request answering, order processing, unique interface for the customer concerning complex payment regulation, consignment stock management, data management for order forecasts, customer dossiers, price lists, etc. 
- The product coordination office in interaction with the manufacturing plant: consolidation of logistics and transport office with the production planning and scheduling office in order to create an office, called product coordination office, production scheduling management and industrial plant tests, allotment management, customer returns, follow-up of performance indicators (overall equipment efficiency, delivery performance on time in full, etc.).

\subsection{Process redesigning results}

The process redesigning effort allowed the company to simplify its organization by reducing the number of entities and services. The company's supply chain has thus become clearer and more efficient because on one hand, it is more customer oriented (assistantship office consistence and permanence vis-à-vis the customer, production location closeness through the product coordination), and on the other hand there is a facilitated access to training for the commercial assistants (thanks to their company location proximity). Moreover, money-saving benefits have been registered through the regrouping of different offices and allowed the company to reduce the charges of the former assistantship offices and to have them under control.

\section{Conclusions}

The project was carried out through the following steps: 1) Macro cartography of the existing activities in the "as is" process, 2) analysis of the "as is" process and sub processes through the SCOR-model standardized sequence of activities, 3) comparison of each activity in the processes with the help of company and SCOR inputs, outputs, information used and created to identify the main differences between the existing situation and the SCOR ideal process.

Thanks to the new process organization, the new commercial assistantship office and the logistics and transport office, which were linked in an important manner creating for the customer a certain confusion about the company reactivity and responsiveness, were separated. This also helped to clarify the roles of every actor and to allow the customer to dispose of one unique point of contact within the company. As for the logistic and transport office regrouping with the production planning and scheduling office, it allowed evolving towards an integrated and complete order management.

The process redesigning of the concerned offices has also consequences on employment because the different jobs has to be reassigned. The existing staff was therefore reorganized according to the required competencies for the new process organization. In case of gaps between detained and requires competency, certain actors were assigned to other jobs and new actors hired.

However, a company should not embark on such a process reengineering analysis without having profoundly thought about the reasons and the possible obstacles concerning this company and process reorganization. Using SCOR and 
BPR for the process optimization, one needs to simplify and base the process configuration on two levels: the material flow and the information/work flow. Process reorganization needs to be made in light of people, process and technology. Not only the tactical and strategic processes need to be optimized, but also the individual user's motivation and the technology they use to operate. Without all three molded into a final methodology, continuous improvement cannot take place.

\section{References}

1. Aguilar-Saven R.S., “ Business process modelling: Review and framework”, Int. J. Production Economics 90 (2004) pp 129-149.

2. Choi T.Y., Hong Y., "Unveiling the structure of supply networks: case studies in Honda, Acura, DaimlerChrysler". Journal of Operations Management 20 (5), 2002, 469-493.

3. Danese P., Romano P., Vinelli A., "Managing business processes across supply networks: the role of coordination mechanisms", Journal of Purchasing \& Supply Management 10 (2004) 165-177.

4. Davenport T.H., "Process Innovation: Reengineering Work Through Information Technology”, Harvard Business School Press, Boston, 1993.

5. Frayret J.M., D’Amours S., Montreuil B., "Coordination and control in distributed and agent-based manufacturing systems", Production Planning\&Control, Vol. 15, No. 1, January 2004, 42-54.

6. Grandori A., "An organizational assessment of interfirm coordination modes", Organization Studies 18 (6), 1997, 897-925.

7. Hammer M., Champy J., "Reengineering the corporation: A manifesto for business revolution", Harper Collins, New York, 1993.

8. Kramer R.M., Tyler T.R., "Trust in Organizations: Frontiers of Theory and Research”, Sage Publications, Berkeley, CA, 1995.

9. Lacity M.C., Hirschheim R., "The Information Systems Outsourcing Bandwagon", Sloan Management Review, 1993, 73-86.

10. Lambert D. M., Cooper M. C., Pagh J. D., "Supply Chain Management: Implementation Issues and Research Opportunities", International Journal of Logistics Management 9 (2), (1998), 1-19.

11. Lambert D.M., García-Dastugue S.J., Croxton K.L. "An evaluation of processoriented Supply Chain Management Frameworks" Journal of Business Logistics, Vol. 26 (1), 2005, 25-51. 
12. Lindsay A., Downs D., Lunn K., "Business processes - attempts to find a definition” Information and Software Technology 45 (2003) 1015-1019.

13. Malone T. W., Crowston K., "What is Coordination Theory and How Can It Help Design Cooperative Work Systems", in Proceedings of the Conference on Computer Supported Cooperative Work, Los Angeles, California, October, 1990, $15 \mathrm{p}$.

14. Mentzer M.S., "Two heads are better than one if your company spans the globe", Academy of Management Executive, no 13, p. 89-90, 1999.

15. Plavia P.C., "A dialectic view of information systems outsourcing : Pros and cons”, Information \& Management, no. 29, 1995, 265-275.

16. Rittenberg L., Covaleski M.A., Internalization versus externalization of the internal audit function: an examination of professional and organizational imperatives, Accounting, Organizations and Society, no. 26, 2001, 617-641.

17. Romano P., "Co-ordination and integration mechanisms to manage logistics processes across supply networks" Journal of Purchasing \& Supply Management 9 (2003) 119-134.

18. Shena H., Wallb B., Zarembab M., Chena Y., Browne J., "Integration of business modelling methods for enterprise information system analysis and user requirements gathering", Computers in Industry 54 (2004) pp 307-323.

19. Stevens G., "Integrating the supply chain", Physical Distribution \& Materials Management, no. 19 8, p.3-8, 1998.

20. Thompson J.D., "Organizations in Action », USA: McGraw-Hill, 1967. 